\title{
Investigation of Piperazine and its Derivatives as Vapor Phase Corrosion Inhibitors for Mild Steel
}

\author{
M.A. Quraishi ${ }^{1}$, F.A. Ansari ${ }^{*}, 1$ and J. Rawat ${ }^{2}$ \\ ${ }^{I}$ Department of Applied Chemistry, Institute of Technology, Banaras Hindu University, Varanasi -220 005, U.P., India \\ ${ }^{2}$ Bharat Petroleum Corporation Limited, Greater Noida, Uttar Pradesh, India
}

\begin{abstract}
Piperazine and its derivatives such as phosphates, carbonates, benzoates, cinnamate and maleate were developed and investigated as vapor phase corrosion inhibitors by weight loss, potentiodynamic polarization methods for mild steel. All of these compounds have shown good inhibition efficiency for mild steel after 30 days under continuous condensation test (CT). The potentiodynamic polarization studies have shown predominantly anodic behavior of all these compounds.
\end{abstract}

Keywords: Corrosion inhibition, vapor phase corrosion inhibitors, piperazine, mild steel.

\section{INTRODUCTION}

Vapor phase corrosion inhibitors are best known to protect metallic articles and equipments during storage and transportation [1-4]. There are numerous investigations on corrosion inhibition studies by aliphatic amines, salicylic amines and their salts as vapor phase corrosion inhibitors for various industrial metals and alloys [5-8]. However, investigations bearings Oxygen, Nitrogen or Sulphur atoms in the ring have received little attention. Benzotriazole has been reported as effective corrosion inhibitor for copper and its alloys $[9,10]$. Subramaian et al. [11] has recently studied the corrosion inhibition behavior of morpholine and its three salts, such as morpholine carbonate, borate and phosphate, of these, morpholine and its carbonate derivatives exhibited 90 percent and 85 percent inhibition efficiency, while other salts gave less than 40 per cent inhibition efficiency. Fifty-three products [12], mostly carboxylate salts of amines, were evaluated as vapor phase corrosion inhibitors for mild steel, among them, fifteen compounds showed effectiveness in excess of $90 \%$. Morpholine was the most effective amine and caprylic acid as the most effective acid constituent. Daquan Zhang et al. [13] developed bis-piperidiniummethylurea as volatile corrosion inhibitor for temporary protection of carbon steel.

In the present study, the authors have studied the inhibiting properties of five vapor phase corrosion inhibitors, such as piperazine (P), piperazine dinitrobenzoate (PDNB), piperazine dimaleate (PDM), piperazine diphosphate (PDP) and piperazine dicarbonate (PDC) on corrosion of mild steel.

\section{EXPERIMENTAL}

Prior to all measurements, cold rolled mild steel samples of size $2 \times 2.5 \times 0.25 \mathrm{~cm}$ having composition (wt $\%$ ): $0.14 \%$ C, $0.35 \% \mathrm{Mn}, 0.17 \% \mathrm{Si}, 0.025 \% \mathrm{~S}, 0.03 \% \mathrm{P}$ and balance Fe.

*Address correspondence to this author at the Department of Applied Chemistry, Institute of Technology, Banaras Hindu University, Varanasi 220 005, U.P., India; Tel: +91-945603326; Fax: +91-542-2368428;

E-mail: farhat_aisha16@yahoo.com
The strips were polished by emery paper of $1 / 0,2 / 0$ and $3 / 0$ rinsed with double distilled water, degreased and dried at room temperature. Piperazine and its derivatives such as carbonate, nitro benzoate, maleate and phosphate, were synthesized by reacting the piperazine with carbon dioxide, nitro benzoic acid, maleic acid and phosphoric acid respectively. The names, molecular structures of the compounds are given in Table $\mathbf{1}$.

Weight loss experiments were carried out in presence and absence of inhibitors at various concentrations, using tight fitting rubber cork jars (Fig. 1). The mild steel specimens was level mounted on the top of the beaker by transparent adhesive tapes and just below these specimens were kept vapor phase inhibitor samples in a small bottle. These jars were kept at $100 \%$ relative humidity at $40^{\circ} \mathrm{C}$ for 8 hours and then for 16 hours under the room temperature [14] in order to allow continuous condensation of moisture on metal specimen. This set up was kept for 30 days.

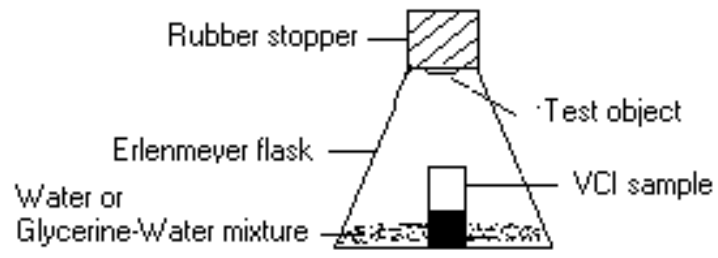

Fig. (1). Experimental setup for weight loss experiments.

The inhibition efficiency (IE \%) was determined by the following equation:

$$
\text { I.E. }(\%)=\frac{W o-W i}{W o} \times 100
$$

where $W o$ and $W i$ is the weight loss value in the absence and presence of inhibitor

Potentiodynamic polarization studies were performed using EG\&G PARC potentiostat / Galvanostat (model 173) and $\mathrm{X}-\mathrm{Y}$ recorder (Model RE0089). The polarization was carried out at a sweep rate of $1 \mathrm{mVs}^{-1}$. The potential was carried out from OCP within the range of $\pm 200 \mathrm{mV}$ and the 
Table 1. Molecular Structures of the Inhibitors Used

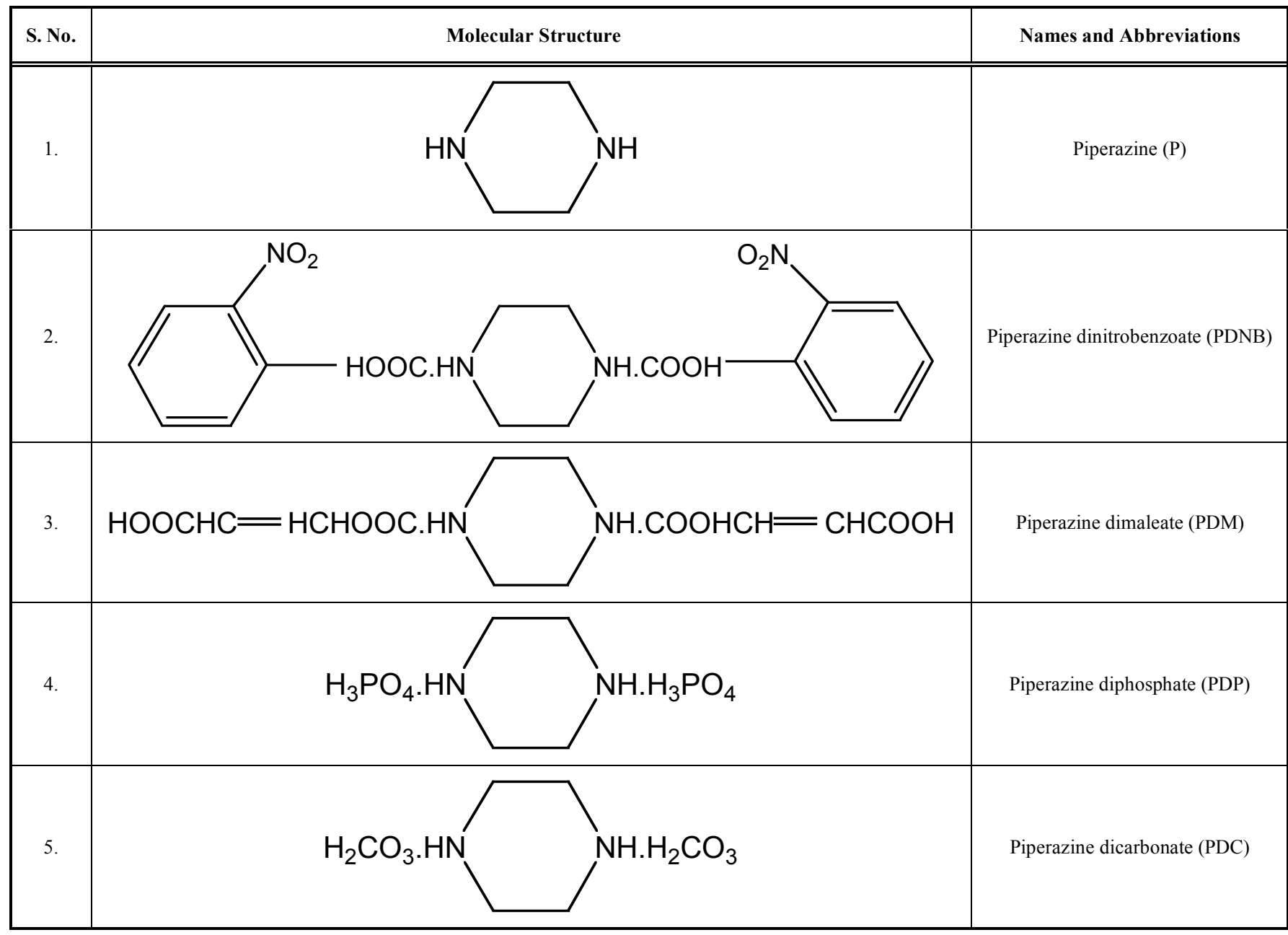

electrodes were polarized from cathodic to anodic direction. The cell assembly (Fig. 2) consisted of mild steel as a working electrode, platinum foil as counter electrode and a saturated calomel electrode (SCE) as the reference electrode. All the experiments were carried out in $1 \mathrm{~N} \mathrm{Na}_{2} \mathrm{SO}_{4}$ solution as electrolyte.

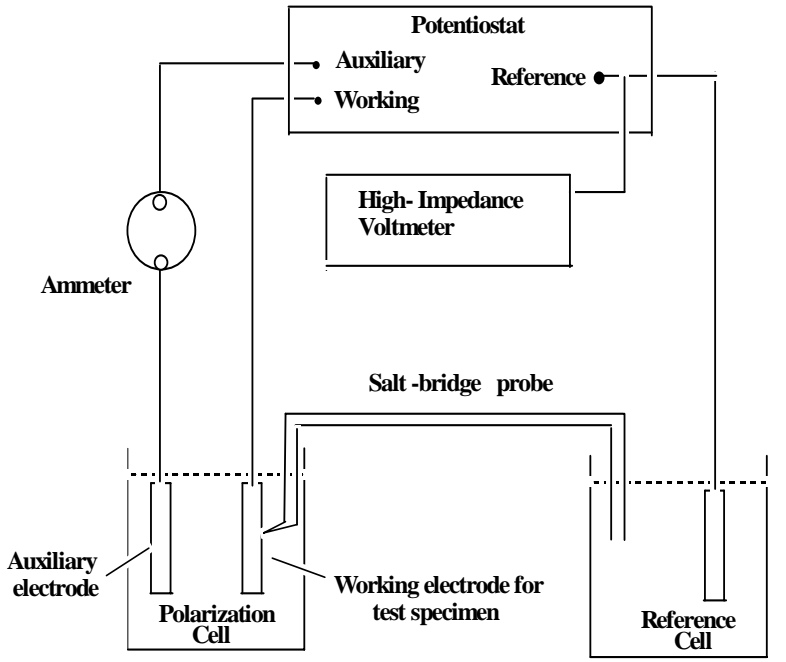

Fig. (2). Instrumental setup for electrochemical polarization experiments.
The corrosion inhibition efficiency (\%IE) was evaluated from the measured $i_{\text {corr }}$ values using the relationship:

I.E. $(\%)=\frac{{ }^{{ }^{O}}{ }_{\text {corr }}-i^{\prime}{ }_{\text {corr }}}{{ }^{O}{ }^{O} \text { corr }} \times 100$

where, $i_{\text {corr }}^{o}$ and $i_{\text {corr }}^{i}$ are the corrosion current densities in the absence and in presence of inhibitor.

\section{RESULTS AND DISCUSSIONS}

\subsection{Weight Loss Studies}

The values of inhibition efficiency (IE) and corrosion rate $(\mathrm{CR})$ obtained at different concentrations of inhibitors are given in Table 2. All the VCI's have shown good inhibition efficiencies which may be attributed to the formation of physical barrier between metal and corrosive environment by the interaction of metal and inhibitor molecule. However, the difference in their inhibiting action can be explained on the basis of their molecular structure.

The results of weight loss studies clearly demonstrate the superior performance ( $>99$ percent inhibition efficiency) of Piperazine derivatives containing organic anions such as dinitrobenzoate (PDNB) and maleate (PDM) than those containing inorganic anions such as carbonate (PDC) and phosphate (PDP). In the present investigation, nitrobenzoate 
salt of piperazine (PDNB) exhibited the best performance due to presence of nitro group, aromatic ring and carboxylate anion. Better inhibitive action of PDM is attributed to the presence of $\pi$-bond between carbon atoms $(-\mathrm{C}=\mathrm{C}$-) which facilitates greater adsorption of inhibitor molecule on the mild steel surface.

Table 2. Weight Loss Parameter Obtained from Different Concentration of Piperazine and its Derivatives at $40^{\circ} \mathrm{C}$ and $100 \%$ Relative Humidity for 30 Days

\begin{tabular}{|c|c|c|c|}
\hline System & Weight Loss (mg) & $\begin{array}{c}\text { Inhibition } \\
\text { Efficiency (\%) }\end{array}$ & $\begin{array}{l}\text { Corrosion Rate } \\
(\mathrm{mmpy}) \times \mathbf{1 0}^{-3}\end{array}$ \\
\hline Blank & 38.5 & -- & 5.95 \\
\hline \multicolumn{4}{|c|}{ Piperzine (P) } \\
\hline 250 & 6.6 & 82.86 & 1.20 \\
\hline 500 & 2.1 & 94.55 & 3.25 \\
\hline 750 & 1.2 & 96.88 & 1.85 \\
\hline 1000 & 0.5 & 98.70 & 0.77 \\
\hline \multicolumn{4}{|c|}{ Piperazine Dinitrobenzoate (PDNB) } \\
\hline 250 & 2.3 & 94.03 & 3.56 \\
\hline 500 & 1.9 & 95.06 & 2.94 \\
\hline 750 & 0.4 & 98.96 & 0.62 \\
\hline 1000 & 0.2 & 99.48 & 0.31 \\
\hline \multicolumn{4}{|c|}{ Piperazine Dimaleate (PDM) } \\
\hline 250 & 3.0 & 92.21 & 4.46 \\
\hline 500 & 0.8 & 97.92 & 1.24 \\
\hline 750 & 0.3 & 99.22 & 0.46 \\
\hline 1000 & 0.2 & 99.48 & 0.31 \\
\hline \multicolumn{4}{|c|}{ Piperazine Diphosphate (PDP) } \\
\hline 250 & 2.0 & 94.81 & 3.09 \\
\hline 500 & 1.6 & 95.84 & 2.48 \\
\hline 750 & 0.8 & 97.92 & 1.24 \\
\hline 1000 & 0.6 & 98.44 & 0.93 \\
\hline \multicolumn{4}{|c|}{ Piperazine Dicarbonate (PDC) } \\
\hline 250 & 4.1 & 89.35 & 6.35 \\
\hline 500 & 1.2 & 96.88 & 1.86 \\
\hline 750 & 0.9 & 97.66 & 1.39 \\
\hline 1000 & 0.7 & 98.18 & 1.08 \\
\hline
\end{tabular}

\subsection{Potentiodynamic Polarization Studies}

The polarization behavior of mild steel in $1 \mathrm{~N} \mathrm{Na}_{2} \mathrm{SO}_{4}$ containing different concentrations of inhibitors is shown in Fig. (3a-e) and the electrochemical parameters derived from Tafel plots are summarized in Table 3. It is evident from the results that $\mathrm{I}_{\text {corr }}$ (Corrosion Current) values of all the inhibited mild steel coupons are low as compared to uninhibited mild steel, suggesting that all the Piperazine derivatives are effective corrosion inhibitors. It is also seen that all these samples shift the corrosion potential significantly to noble direction therefore they are predominantly anodic inhibitors.

Table 3. Potentiodynamic Polarization Parameters Obtained from Different Concentration of Piperazine and its Derivatives

\begin{tabular}{|c|c|c|c|}
\hline Concentration ppm & $\begin{array}{c}\text { Corrosion } \\
\text { Potential } \\
\mathbf{E}_{\text {corr }}(\mathrm{mV})\end{array}$ & 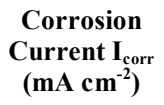 & $\begin{array}{c}\text { Inhibition } € \\
\text { Efficiency } \\
\text { IE }(\%)\end{array}$ \\
\hline Blank & -562 & 0.25 & -- \\
\hline \multicolumn{4}{|l|}{ Piperzine (P) } \\
\hline 250 & -500 & .064 & 74.4 \\
\hline 500 & -490 & .060 & 76.0 \\
\hline 750 & -420 & .052 & 79.2 \\
\hline 1000 & -480 & .048 & 80.8 \\
\hline \multicolumn{4}{|c|}{ Piperazine Dinitrobenzoate (PDNB) } \\
\hline 250 & -432 & .074 & 70.4 \\
\hline 500 & -468 & .068 & 72.8 \\
\hline 750 & -358 & .056 & 77.6 \\
\hline 1000 & -346 & .044 & 82.4 \\
\hline \multicolumn{4}{|c|}{ Piperazine Dimaleate (PDM) } \\
\hline 250 & -510 & .076 & 69.6 \\
\hline 500 & -370 & .060 & 76.0 \\
\hline 750 & -360 & .058 & 76.8 \\
\hline 1000 & -460 & .050 & 80.0 \\
\hline \multicolumn{4}{|c|}{ Piperazine Diphosphate (PDP) } \\
\hline 250 & -480 & .058 & 76.8 \\
\hline 500 & -470 & .055 & 78.0 \\
\hline 750 & -516 & .045 & 82.0 \\
\hline 1000 & -460 & .040 & 84.0 \\
\hline \multicolumn{4}{|c|}{ Piperazine Dicarbonate (PDC) } \\
\hline 250 & -490 & .074 & 70.4 \\
\hline 500 & -390 & .060 & 76.0 \\
\hline 750 & -470 & .058 & 76.8 \\
\hline 1000 & -425 & .048 & 80.8 \\
\hline
\end{tabular}

\subsection{Mechanism of Corrosion Inhibition}

Vapor phase inhibitors can inhibit corrosion of metals in the following ways:

1. By saturating the space with their vapors and reducing the relative humidity below the critical value [15].

2. By alkalizing the medium to $\mathrm{pH}$ values at which the rate of corrosion becomes significantly low [8].

3. By producing a high ohmic resistance on the metal surface which reduces the corrosion current to a minimum value [16]. 

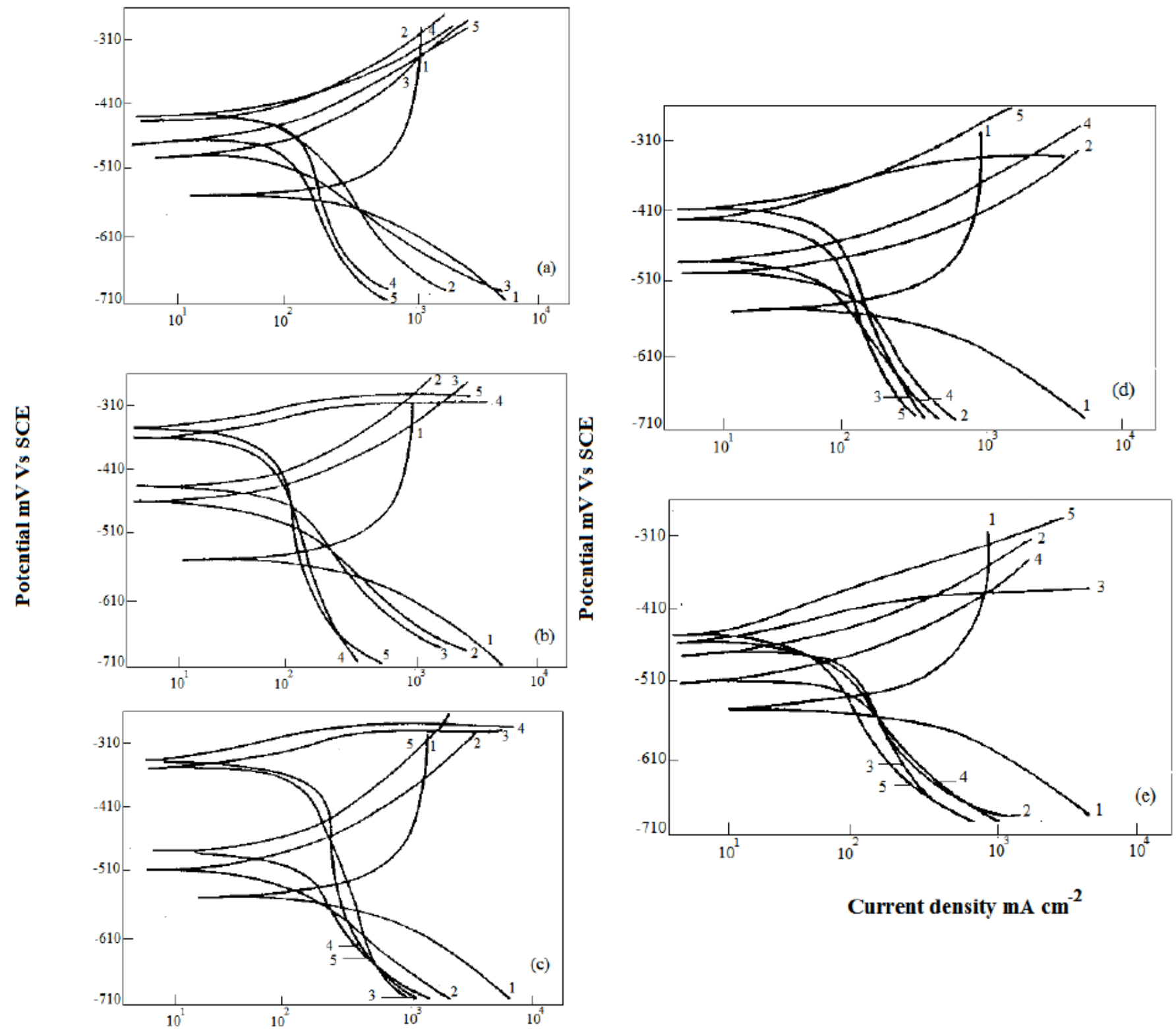

Current density $\mathbf{m A ~} \mathrm{cm}^{-2}$

Fig. (3). Potentiodynamic polarization curves for mild steel inhibited with different concentration of: (a) Piperazine. (b) Piperazine dinitrobenzoate. (c) Piperazine dimaleate. (d) Piperazine diphosphate. (e) Piperazine dicarbonate. 1. Blank, 2. 250 ppm, 3. 500 ppm, 4. 750 ppm, 5. 1000 ppm.

4. By rendering the metal surface hydrophobic thereby preventing the reaction of metal with the environment [17].

\section{CONCLUSIONS}

The vapor phase corrosion inhibition of mild steel carried out by using Piperazine and its derivatives shows good inhibition efficiency. Inhibition of corrosion is by the formation of physical barrier between metal and corrosive environment by the interaction of metal and inhibitor molecules. The inhibitive performance of all inhibitors increases on increasing the inhibitor concentration. PDNB gave the best performance among all compounds giving 99.48 percent inhibition efficiency at $1000 \mathrm{ppm}$ concentration. All inhibitors have shown anodic behavior by retarding the anodic dissolution of mild steel by blocking the active sites on the mild steel surface.

\section{ACKNOWLEDGEMENT}

One of the authors F. A. Ansari, thankfully acknowledges CST UP, Lucknow, India for the award of Young Scientist.

\section{REFERENCES}

[1] McConnell, R. Volatile corrosion inhibitors offer effective protection for processing and shipment of metal-based products. Metal Finishing, 2008, 106, 23-27.

[2] Andreev, N. N.; Kuzentsov, Y. I.; Fedotova, T. V. On corrosion protection of steel with solutions of volatile inhibitors. Protect. Metals, 2001, 37, 1-8.

[3] Furman, A. Test methods for vapor corrosion inhibitors. Proceedings $9^{\text {th }}$ Europ Symp on Corrosion Inhibitors. Ferrara, 2000, 465-479.

[4] Batidas, D. M.; Cano, E.; Mora, E. M. Volatile corrosion inhibitors: a review. Anti-Corrosion Meth. Mater., 2005, 52, 71-77.

[5] Sastri, V. S. Corrosion Principle and Application. John Wiley and Sons., New York, 1998, p. 787. 
[6] Gao, G.; Liang, C. H. 1,3-bis-diethylamino-propan-2-ol as volatile corrosion inhibitor for Brass. Corrosion Sci., 2007, 49, 3479-3493.

[7] Subramania, A.; Sathiya Priya, A. R.; Vasudevan, T. Diethylamine phosphate as VPI for steel component. Mater. Chem. Phys., 2006, 100, 193-197.

[8] Zang, D. Q.; Gao, L. X.; Zhou, G. D.; Polyamine compounds as a volatile corrosion inhibitor for atmospheric corrosion of mild steel. Mater. Corrosion, 2008, 58, 594-598.

[9] Rammelt, U.; Koehler, S.; Reinhard, G. Use of vapor phase corrosion inhibitors in packages for protecting mild steel against corrosion. Corrosion Sci., 2009, 51, 921-925.

[10] Bellakhal, N.; Dachraoui, M. Study of the benzotriazole efficiency as a corrosion inhibitor for copper in humid air plasma. Mater. Chem. Phys., 2004, 85, 366-369.

[11] Subramanian, A.; Gopalakrishnan, R.; Boopathi, C.S.; Balakrishnan, K.; Vasudevan, T.; Natesan, M.; Rangaswami, N. S.; Bull Electrochemistry, Morpholine and its derivatives as vapor phase corrosion inhibitors for mild steel. Bull. Electrochem., 1998, $14,289-290$
[12] Vuorimen, E.; Skinner, W. Amine carboxylate as vapor phase corrosion inhibitors. Br. Corrosion J., 2002, 37, 159-160.

[13] Zhang, D.; An, Z.; Pan, Q.; Gao, L.; Zhou, G. Volatile corrosion inhibitor film formation on carbon steel surface and its inhibition effect on the atmospheric corrosion of carbon steel. Appl. Surf. Sci., 2006, 253, 1343-1348.

[14] Rocca, E.; Rapin, C.; Mirambet, F. Inhibition treatment of the corrosion of lead artefacts in atmospheric conditions and by acetic acid vapor: use of sodium decanoate. Corrosion Sci., 2004, 46, 653-665.

[15] Andreev, N. N.; Andreeva N. P.; Vartapetyan, R. S.; Kuznetsov, Y. I.; Fedotova, T. V. Volatile corrosion inhibitors based on ethanolamines. Protect Metals, 1997, 33, 470-473.

[16] Amar, H.; Braisaz, T.; Villemin, D.; Moreau, B. Thiomorpholin-4 ylmethyl-phosphonic acid and morpholin-4-methyl-phosphonic acid as corrosion inhibitors for carbon steel in natural seawater. Mater. Chem. Phys., 2008, 110, 1-6.

[17] Boyle, B. A look at development in vapor phase corrosion inhibitors, Metal Finishing, 2004, 702, 37-41.

(C) Quraishi et al.; Licensee Bentham Open.

This is an open access article licensed under the terms of the Creative Commons Attribution Non-Commercial License (http: //creativecommons.org/licenses/by$\mathrm{nc} / 3.0 /$ ) which permits unrestricted, non-commercial use, distribution and reproduction in any medium, provided the work is properly cited. 